\title{
Orçamento Participativo e cultura política: Explorando as relações entre inovação institucional, valores e atitudes políticas
}

\author{
Julian Borba ${ }^{1}$ \\ Ednaldo Aparecido Ribeiro²
}

\section{Resumo}

O Orçamento Participativo (OP) tem sido apontado pela literatura como uma inovação institucional capaz de produzir impactos políticos institucionais e culturais. Entre os últimos, aponta-se para sua capacidade de alterar padrões de cultura política estabelecidos no país, como o clientelismo. Os dados empíricos que sustentam tais afirmações são, em geral, precários. O presente trabalho propõe-se a analisar tal problemática da relação entre OP e cultura política, tomando como base empírica um survey aplicado na cidade de Porto Alegre em 2000. Utilizamos técnicas multivariadas de análise de dados (modelo de regressão), que nos permitiu inserir elementos propriamente explicativos na análise e verificar se a participação no OP ou o tempo de participação constitui-se em um bom preditor de cultura cívica e capital social.

Palavras-Chave: Democracia. Cultura política. Orçamento participativo. Capital social. Políticas públicas.

1 Professor do Departamento de Sociologia e Ciência Política da Universidade Federal de Santa Catarina; Pesquisador do CNPq; Doutor em Ciência Política pela Universidade Federal do Rio Grande do Sul (UFGRS).

2 Professor do Departamento de Ciências Sociais da Universidade Estadual de Maringá (UEM); Doutor em Sociologia pela Universidade Federal do Paraná (UFPR). 


\section{Orçamento Participativo e Cultura Política: Explorando as relações entre inovação institucional, valores e atitudes políticas \\ Julian Borba • Ednaldo Aparecido Ribeiro}

\section{Introdução}

\section{$\mathrm{O}$}

Orçamento Participativo (OP) tem sido apontado pela literatura como uma inovação democrática (AVRITZER; NAVARRO, 2003) portadora de virtudes, seja no plano da sua capacidade de racionalização da ação estatal (FEDOZZI, 1997), seja no potencial de alterar padrões históricos de relacionamento Estado x Sociedade no Brasil, como o clientelismo (ABERS, 1996). Estudos recentes também apontam para eventuais impactos da experiência nos padrões atitudinais e comportamentais dos participantes, de modo que o OP produziria algum tipo de aprendizado político (FEDOZZI, 2002; BAIOCHI, 2005; LÜCHMANN, 2008).

Considerando a questão do impacto do OP nos padrões atitudinais e comportamentais dos cidadãos, o presente trabalho propõe-se a analisar se a participação nesse experimento pode ser um preditor de indicadores relacionados ao que a literatura convencional denomina de comunidade cívica e capital social. A ideia é confrontar tais indicadores com outras variáveis geralmente presentes na literatura, através da construção de modelos multivariados que permitem avaliar comparativamente impactos produzidos por distintas medidas independentes.

As razões para tal esforço de investigação são de ordens empírica e teórica: em termos empíricos pela inexistência de consenso quanto a real capacidade do OP em promover mudança de valores e comportamentos. Com relação à questão teórica, o exame de alguns indicadores relacionados ao conceito de capital social nos possibilita testar (e eventualmente questionar) o chamado determinismo culturalista da teoria desenvolvida por Robert Putnam. Nesse sentido, questionamos se é possível, a partir de inovações institucionais participativas, construir tradições cívicas.

A base empírica utilizada no trabalho refere-se à experiência do Orçamento Participativo desenvolvida em Porto Alegre e foi construída por um survey sobre comportamento político e eleições 
(NUPESAL, 2000), aplicado à amostra representativa da população municipal $(\mathrm{n}=533)^{3}$.

O trabalho está organizado em quatro partes: na primeira, discutimos as questões teóricas envolvidas em tal debate. Aí também fazemos uma apresentação da literatura que estudou o OP de Porto Alegre sob a ótica da cultura política. Na segunda, apresentamos a metodologia utilizada na análise dos dados para, na parte três, discutir um conjunto de resultados de testes bivariados e multivariados. Nas considerações finais, são estabelecidas algumas conclusões e perspectivas para novos trabalhos.

\section{Comunidade cívica e capital social em Robert Putnam}

Muito mais do que apontar para as origens, limites, contradições e/ou perspectivas da teoria do capital social, nosso objetivo aqui será apresentar a estrutura lógica contida no argumento de Robert Putnam e colaboradores, no livro Comunidade e Democracia. Apresentaremos os principais argumentos contidos na construção putniana, bem como as questões relacionadas às possibilidades de se construir capital social via reformas institucionais ${ }^{4}$.

Interessa-nos aqui, sobretudo, discutir questões analíticas e lógicas do argumento de Putnam e colaboradores, em especial às relações entre valores e instituições. Em outras palavras, pretendemos problematizar em que medida valores moldam ou são moldados por instituições. Ou, qual a capacidade de as instituições produzirem valores?

3 Para maiores detalhes sobre plano amostral, ver NUPESAL, 2000.

4 O trabalho de Putnam e colaboradores tem sido objeto de grande debate no âmbito da Ciência Política, cujos desdobramentos estão além das pretensões deste artigo. No que se refere especificamente ao tema deste artigo (a relação entre inovações institucionais e capital social), ver em especial: Rothstein (2001), Evans (1996), Hooghe; Stolle (2003), Uslaner (2003). Os referidos autores apontam para uma direção de causalidade inversa à de Putnam, onde os arranjos desempenhariam papel central na produção de confiança social e cooperação. Na literatura nacional, ver em especial: Santos (2004), Salej (2005) e Baquero (2003). 


\section{Orçamento Participativo e Cultura Política: Explorando as relações entre inovação institucional, valores e atitudes políticas \\ Julian Borba • Ednaldo Aparecido Ribeiro}

A obra em questão está fundamentada em três grandes conceitos: "desempenho institucional", "comunidade cívica" e "capital social". Os autores tomam como ponto de partida o experimento da descentralização realizada na Itália, que os permitiu avaliar o desempenho institucional a partir de um "marco zero", ou seja, as mesmas instituições foram criadas ao mesmo tempo, tendo igual desenho para todas as regiões daquele país. O esforço analítico foi no sentido de pensar quais as variáveis influenciam e/ou determinam o desempenho dessa nova institucionalidade.

Foram vinte anos de pesquisa, em um trabalho destinado a explicar por que, apesar do marco zero institucional, o desempenho das novas instituições teria sido diferente quando se comparavam as regiões do norte com as do sul do país. Para tanto, construíram vários indicadores de desempenho institucional que foram verificados empiricamente a partir de uma bateria de testes com possíveis variáveis independentes ${ }^{5}$. Suas conclusões indicam que a existência de uma comunidade cívica seria um forte preditor no desempenho das instituições (mais, inclusive, do que o grau de desenvolvimento econômico da região).

Tomando como referência a teorização de Tocqueville, "comunidade cívica" é caracterizada por "[...] cidadãos atuantes e imbuídos de espírito público, por relações políticas igualitárias, por uma estrutura social firmada na confiança e colaboração" (PUTNAM et al., 2002, p. 31). Os indicadores centrais utilizados pelos autores quanto à existência de comunidades cívicas são: associações, informações, participação política e voto preferencial. Sua tese é a de que:

[...] a comunidade cívica é um determinante mais forte que o desenvolvimento econômico [...]. Quanto mais cívica a região, mais eficaz o seu governo [...]. As regiões onde há muitas associações cívicas, muitos leitores de jornais, muitos eleitores politizados e menos clientelismo parecem contar com governos mais eficientes. (PUTNAM et al., 2002, p. 112-113, grifos nossos).

5 Para uma discussão de ordem conceitual e metodológica de Comunidade e democracia, vide Reis (2003). 
Demonstrada a forte correlação entre comunidade cívica e desempenho institucional, os autores vão desenvolver uma explicação teórica para os achados de sua pesquisa. É aí que entra o conceito de capital social. Em um diálogo com a literatura da racional choice, formulam a tese de que os laços de confiança desenvolvidos numa comunidade cívica conformam um tipo de capital (o social) que é capaz de superar os dilemas da ação coletiva, promovendo a cooperação social. Trata-se de "[...] características da organização social, como confiança, normas e sistemas, que contribuem para aumentar a eficiência da sociedade, facilitando as ações coordenadas" (PUTNAM et al., 2002, p. 177). Nesse sentido, "quanto mais elevado o nível de confiança numa comunidade, maior a probabilidade de haver cooperação. E a própria cooperação gera confiança. A progressiva acumulação de capital social é uma das principais responsáveis pelos círculos virtuosos da Itália cívica" (PUTNAM et al., 2002, p. 180).

Veja-se que o argumento conduz a uma estrutura de causalidade onde o capital social, entendido a partir das ideias de confiança generalizada e sistemas de participação cívica, explicaria o desempenho institucional.

Nessa perspectiva, os resultados da pesquisa causam desesperança para aqueles que apostam nas virtudes das inovações institucionais, pois, segundo os autores, o capital social é produto do "longo prazo", de um longo processo de maturação onde se produzem as condições para a confiança generalizada, que no caso estudo sobre a Itália, vão ser buscadas no Século XI e mais especificamente na Renascença italiana. No capítulo final do seu livro, quando tratam das lições da experiência italiana, narram os comentários de um presidente de uma região não cívica ao tomar contato com os resultados do livro. Diz ele: "Isso é aconselhar o desespero! O que vocês estão me dizendo é que nada do que eu venha a fazer melhorará nossas perspectivas de êxito. $O$ destino da reforma já está traçado há séculos" (PUTNAM et al., 2002, p. 193).

Os autores de Comunidade e democracia desenvolvem uma argumentação em grande parte negligenciada pelos seus críticos. 


\section{Orçamento Participativo e Cultura Política: Explorando as relações entre inovação institucional, valores e atitudes políticas \\ Julian Borba • Ednaldo Aparecido Ribeiro}

Afirmam eles que os resultados da pesquisa "estão longe de ser um convite à inércia" (2002, p. 193), e sim que a segunda lição a ser tirada da experiência italiana é que:

Mudando-se as instituiç̧ões formais pode-se mudar a prática política [...], a mudança institucional refletiu-se (gradualmente) na mudança de identidades, valores, poderes e estratégias. Tais tendências manifestaram não apenas no norte, mas também no sul [...] a reforma social propiciou aprendizado social. (idem).

Porém, logo em seguida alertam: "[...] a última lição dessa pesquisa é que a história institucional costuma evoluir lentamente. No que se refere ao fortalecimento das instituições (e não à mera elaboração de cartas constitucionais), o tempo é medido em décadas" (idem) e prossegue: "a história evolui talvez mais lentamente quando se trata de instituir regras de reciprocidade e sistemas de participação cívica, muito embora faltem-nos parâmetros para afirmá-los com certeza" (idem).

Tomando como parâmetro esse diagnóstico de Putnam e colaboradores sobre a path dependence, bem como suas ponderações sobre o impacto de longo prazo das reformas institucionais, cabe entrar em nosso objeto de estudo empírico. Dessa forma, cabe perguntar, considerando-se as especificidades brasileiras, as políticas participativas podem ser consideradas um instrumento eficaz no desenvolvimento de comunidades cívicas e, consequentemente, de capital social? Quais os limites e possibilidades do Orçamento Participativo no sentido de produzir uma sociedade mais cívica e confiante?

\subsection{OP, Capital Social e Comunidade Cívica em Porto Alegre}

Como já destacado, o OP vem se constituindo numa importante inovação na gestão pública brasileira pelo fato de potencialmente romper com as práticas tradicionais exercidas através de relações convencionalmente denominadas de clientelistas e patrimonialistas. 
Tal rompimento se daria pelo caráter universalista e racionalizador existente nas suas regras de funcionamento (FEDOZZI, 1997; 2002), as quais seriam aplicadas através do processo de participação dos cidadãos, quando chamados a participar do processo decisório estatal.

Não é intenção deste artigo discutir os diferentes modelos de OP nem apresentar como se dá a participação dos indivíduos no processo, pois isso já foi feito por outros autores (AVRITZER; NAVARRO, 2003; ABERS, 1999; LÜCHMANN, 2002; PONTUAL, 2001; BORBA; LÜCHMANN, 2007, BAIOCHI, 2005; AVRITZER, 2009; WAMPLER; AVRITZER, 2004). Interessa-nos, sobretudo, identificar a existência ou não de associações entre o OP e alguns indicadores de capital social. Cabe destacar que tal relacionamento é apresentado de forma um tanto quanto intuitiva pela literatura que trata do assunto. Isto se deve ao fato de que a maioria dos estudos sobre o OP toma como foco de análise os próprios participantes do processo (ABERS, 1999; BAIOCHI, 2003; SANTOS, 1998). Nesse sentido, é possível testar apenas se existem mudanças atitudinais e/ou comportamentais entre o público que é ativista do processo. A comparação possível, nesse caso, é entre os novatos e veteranos. Tais estudos, em que pesem os limites quanto à generalização dos resultados, têm atestado os efeitos positivos do OP em termos de mudança na cultura política e/ou aprendizado (FEDOZZI, 2002; LÜCHMANN, 2008; HARTMANN, 2011).

$\mathrm{O}$ uso de metodologias que utilizem amostragens representativas de uma população, incluindo na análise os ativistas e não ativistas do OP, pode complementar os resultados de tais pesquisas e expandir sua capacidade de generalização ${ }^{6}$. Nesse sentido, os poucos estudos que trabalharam com amostras do público massi$\mathrm{vo}^{7}$ apontam para interpretações divergentes.

O trabalho de Lúcio Rennó (2006) estudou os efeitos da participação no OP e em outras modalidades ${ }^{8}$ sobre a informação política.

6 Reafirmamos aqui os apontamentos de Rennó (2006) sobre os ganhos analíticos de se estudar o OP a partir de amostragens probabilísticas.

7 Nos referimos aqui a estudos que trabalham com amostras representativas da população.

8 Associação de bairro, grupo de igreja, sindicato e partido político. 


\section{Orçamento Participativo e Cultura Política: Explorando as relações entre inovação institucional, valores e atitudes políticas \\ Julian Borba • Ednaldo Aparecido Ribeiro}

Os dados foram oriundos de um estudo de painel realizado em Caxias do Sul e Juiz de Fora, no ano de 2002. Suas conclusões indicam que as diferentes modalidades de engajamento político exercem efeitos distintos sobre a informação. Em suas palavras:

Nas variáveis em que a informação é mais escassa, a participação em sindicatos e partidos políticos aumenta significativamente a probabilidade dos eleitores serem mais bem informados. No caso do esforço mais difícil para o entrevistado, lembrar os nomes dos candidatos aos diferentes cargos, a militância em sindicatos, partidos políticos e no OP aumenta a probabilidade de ser mais bem informado. $\mathrm{O}$ OP tem possivelmente um efeito positivo porque conhecer o nome inclui candidatos intimamente ligados a questões locais, tais como os deputados federais. Desse modo, os eleitores podem ficar sabendo deles em meio a discussões sobre os investimentos municipais. (RENNÓ, 2006, p. 339-340).

Por outro lado, Baquero et al. (2005, p. 123), ao testar as relações entre participação no OP e o desenvolvimento de novas atitudes para com o Estado (em particular sobre os impostos), avaliam que:

[...] a situação social e econômica da população exerce influência superior ao OP na estruturação de atitudes e comportamentos em relação aos impostos. Tudo indica que a falta de legitimidade dos impostos, mais do que uma questão de competência cultural, é um problema de solução pragmática.

Por fim, Paulo Krishke (2005a e 2005b), ao comparar a cultura política de porto-alegrenses e curitibanos, identifica na primeira cidade uma série de predisposições atitudinais, no sentido de valorização da política e da participação da população em projetos coletivos. Nesse sentido, seguindo a perspectiva do autor, os vários anos de administração petista e as políticas de OP teriam desempenhado um papel significativo na conformação dessa cultura política.

Considerando essas interpretações discordantes sobre os efeitos atitudinais e comportamentais do OP, o presente trabalho propõe-se a testar alguns indicadores relacionados à teorização sobre capital social oriunda da obra de Robert Putnam. 


\section{Questões metodológicas}

\subsection{Variáveis}

Antes de entrar nos dados, cabem alguns esclarecimentos quanto aos procedimentos metodológicos adotados.

Para analisar os dados, em um primeiro momento buscamos indicadores que nos permitissem testar empiricamente a teoria do capital social. Para isso, tratamos da escolha de variáveis que estivessem o mais proximamente relacionadas a tal formulação teórica. Como vimos acima, Putnam trabalha com distintos planos analíticos, os quais seriam impossíveis de serem operacionalizados em sua totalidade no presente trabalho. Abaixo, listamos alguns dos indicadores que serviram de referência para nossos testes:

- Confiança interpessoal e confiança nas instituições: para Putnam, a confiança "generalizada" é base do capital social. Em suas palavras, "La piedra de toque del capital social es el principio de la reciprocidad generalizada" (PUTNAM, 2002b, p. 175). Para mensurar tal variável, utiliza-se de indicadores objetivos (indicadores de criminalidade, contingente de policiais) e atitudinais (dados de surveys com questões sobre os níveis de confiança nas instituições e/ou na maioria das pessoas);

- Sociedade politizada: a variável "muitos eleitores politizados" foi operacionalizada através do "voto preferencial" (ou partidário em nosso caso);

- Associações: Quantidade de associações cívicas e contingente de filiados as mesmas.

Em nosso estudo, tais variáveis receberam o seguinte tratamento analítico (considerando que todos os nossos dados são provenientes de um survey):

A questão da confiança é analisada em nível interpessoal e também em relação às instituições. Neste último nível, nossos indicadores foram: a) confiança dos cidadãos nos partidos políticos e b) um índice de confiança nas instituições municipais. A partir dessas 


\section{Orçamento Participativo e Cultura Política: Explorando as relações entre inovação institucional, valores e atitudes políticas \\ Julian Borba • Ednaldo Aparecido Ribeiro}

duas medidas foi elaborado um índice que é soma simples das respostas às questões relativas à confiança no Governo Municipal e na Câmara de Vereadores. A confiança interpessoal foi operacionalizada a partir da resposta à pergunta: "você acha que se pode confiar na maioria das pessoas"?

A variável sociedade politizada, por sua vez, foi operacionalizada a partir de três medidas: 1) um índice de participação política eleitoral ${ }^{9}$;2) a resposta relativa à questão sobre o interesse do cidadão pela política; 3 ) a resposta à questão sobre o que é mais importante na hora de votar, o partido ou a pessoa.

Por fim, a variável relativa às associações foi operacionalizada a partir da pergunta sobre a participação dos entrevistados em associações.

Como variável independente principal utilizamos: 1) tempo de participação no OP, com o objetivo de testar os efeitos da inovação institucional nos padrões de civismo e capital social. Todavia, como estratégia de controle desses possíveis efeitos, também adicionamos outras quatro medidas: 2) escolaridade; 3) renda; 4) idade e 5) sexo. A decisão de incluir escolaridade e renda está relacionada ao fato de que ambas são geralmente apontadas por parte da literatura como as de maior capacidade de predição quanto ao engajamento político dos cidadãos ${ }^{10}$. Sexo e idade, ainda que não apareçam com a mesma relevância nos estudos sobre o tema, foram incluídos por se tratarem de importantes atributos demográficos.

\subsection{Procedimentos de análise}

Definidas as variáveis, procedemos às análises em duas etapas distintas. Na primeira foram conduzidos testes bivariados de

9 Foi elaborado um índice de participação eleitoral composto pelas questões: doa dinheiro para campanhas eleitorais; faz trabalho gratuito para a campanha; participa de carreatas e caminhadas; participa de debates e reuniões nas comunidades.

10 Em especial, a literatura tributária da teoria da centralidade. Sobre o tema ver Milbraith (1965). 
associação utilizando o qui-quadrado $\left(\mathrm{X}^{2}\right)$ e também o coeficiente Gamma $^{11}$. Na sequência, para confirmar e aprofundar a compreensão sobre as associações encontradas foram construídos modelos multivariados de regressão linear e logística, dependendo da natureza das variáveis dependentes.

O modelo estatístico-matemático simples de regressão relaciona uma variável $y$, denominada variável resposta ou dependente, com uma segunda medida $x$, chamada de variável explicativa, independente ou preditora. Como no caso dos testes de correlação e associação, esse tipo de análise toma as observações singulares como pares de dados $(x, y)$ relativos às variáveis envolvidas na equação. Quando um determinado valor de $y$ depende parcialmente do valor do seu correspondente $x$ podemos falar de uma relação linear entre essas variáveis. Como trabalhamos com mais de uma variável explicativa nas análises apresentadas ao longo deste trabalho, nos valemos principalmente de modelo de regressão múltipla. Levando em consideração que uma variável dependente geralmente varia em relação a mais de uma medida preditora, esse tipo de procedimento nos permite conhecer a influência de cada uma dessas sobre $y$. Esse procedimento possibilita testar se o relacionamento verificado entre as variáveis envolvidas é realmente válido ou se é espúrio, sobretudo porque podemos controlar os efeitos da nossa variável independente principal com a inclusão de terceiras variáveis nos modelos. Destacamos desde já que nossa intenção com a aplicação dessa técnica estatística não é construir modelos explicativos robustos acerca das variáveis respostas, mas tão somente identificar a intensidade e a consistência do efeito produzido pela participação no Orçamento Participativo sobre cada uma das variáveis dependentes mencionadas anteriormente.

Em alguns casos, entretanto, a natureza das variáveis dependentes não possibilita o emprego dessa técnica, que pressupõe a natureza quantitativa das medidas. Nos momentos em que trabalhamos

11 Os testes Gamma foram conduzidos apenas nos casos em que a análise de associação com qui-quadrado revelaram níveis de significância estatística mínima. 


\section{Orçamento Participativo e Cultura Política: Explorando as relações entre inovação institucional, valores e atitudes políticas \\ Julian Borba • Ednaldo Aparecido Ribeiro}

com variáveis dicotômicas, como no caso da confiança interpessoal, empregamos modelos de regressão logística, especialmente desenvolvidos para esse nível de mensuração (POWERS; XIE, 2008).

\section{Resultados}

Antes de entrar nos resultados de nossas análises, consideramos necessário apresentar alguns dados gerais sobre a pesquisa Comportamento político e eleições (NUPESAL, 2000) no que se refere ao Orçamento Participativo. A referida pesquisa continha quatro perguntas relacionadas ao Orçamento Participativo:

a) O (a) Sr. (a) sabe o que é o Orçamento Participativo?

b) $O$ (a) Sr. (a) já participou de reuniões do Orçamento Participativo?

c) Há quanto tempo participa do Orçamento Participativo?

d) Qual sua opinião sobre o Orçamento Participativo?

No que se refere à primeira questão, $83,5 \%$ dos entrevistados disseram saber o que é Orçamento Participativo.

Em termos de participação (a segunda questão) 23,8\% dos casos válidos da amostra disseram já ter participado do OP, contra $76,2 \%$ que disseram nunca ter participado ${ }^{12}$. Tais dados podem indicar uma superestimação do número de participantes, tendo em vista que ao se considerar o registro de comparecimento às reuniões, se atingiu maior número de participantes entre 2002 e 2003, com um valor total próximo a 21.805 participantes (GUGLIANO, 2010), o que corresponde a pouco mais de $2 \%$ dos eleitores (FEDOZZI, 2007; BANCO MUNDIAL, 2008). Deve-se destacar, no entanto, que nossos dados são do ano de 2000; portanto, todos aqueles que já participaram nos 11 anos anteriores (já que o OP iniciou em 1989) se enquadram na categoria de participantes. Além disso, o registro do número de participantes capta apenas aqueles que compareceram às instâncias formais do OP (Assembleias Comu-

12 O número de participantes do OP por ano pode ser consultado em Gugliano (2010, p. 192). 
nitárias, Fóruns de Delegados, Assembleias Temáticas, Conselho do OP), nas quais não esgotam as possibilidades de participação. Sabe-se que o OP envolve uma gama de esferas informais de participação (LUCHMANN, 2002) que mobilizam os participantes (conselhos populares, associações de moradores, união de vilas etc.). Ao participar dessas esferas, o cidadão está de alguma maneira, vinculado ao OP sem, no entanto, entrar na contabilidade oficial do número de participantes.

Quanto à pergunta sobre o tempo de participação, 32,8\% afirmaram estar participando pela primeira vez do OP. Outros $23,5 \%$ participam há 2 anos, contra $22,7 \%$ que já participam há 3 anos. Por fim, $21 \%$ dos respondentes dizem ter "sempre" participado do OP.

A última questão procurava saber a opinião dos cidadãos sobre o OP. As respostas indicaram uma visão essencialmente positiva sobre a experiência, pois, para $47,3 \%$ dos respondentes, o OP "estimula a participação da população". Para 15,9\% ele "descentraliza as decisões sobre o uso do dinheiro público". Outros $15,4 \%$ concordaram que ele "facilita o controle sobre os gastos e investimentos do governo". Já entre as opiniões negativas, $14 \%$ concordam que o OP "é um instrumento partidário"; outros 6,2\% acreditam que o OP "manipula a população". Por fim, para 1,2\% ele "desvaloriza o papel do legislativo".

Feitas essas considerações gerais sobre as questões relacionadas ao OP, vejamos agora o conjunto de testes que realizamos para verificar o efeito do tempo de participação sobre alguns indicadores de capital social.

\subsection{Confiança}

Começando pela confiança interpessoal, podemos verificar na Tabela 1 que apenas o cruzamento com escolaridade se mostrou estatisticamente significativo, inclusive em um nível bastante exigente (.000). Os testes de qui-quadrado $\left(X^{2}\right)$ revelaram que renda e tempo de OP não se relacionam à confiança interpessoal. 
Orçamento Participativo e Cultura Política: Explorando as relações entre inovação institucional, valores e atitudes políticas

Julian Borba • Ednaldo Aparecido Ribeiro

Tabela 1 - Associações entre renda/escolaridade/tempo de OP e confiança interpessoal (\%)

\begin{tabular}{l|c|c|c}
\cline { 2 - 4 } & \multicolumn{3}{c}{ CONFIANÇA INPERPESSOAL } \\
\cline { 2 - 4 } & Não confia & Depende & Confia \\
\hline RENDA FAMILIAR & & & \\
\hline Menos de 1 SM** & 22,5 & 43,7 & 33,8 \\
\hline De 1 a 5 SM & 30,2 & 37,2 & 32,3 \\
\hline 5 a 10 SM & 25,2 & 38,3 & 36,4 \\
\hline Mais de 10 SM & 22,0 & 35,1 & 42,9 \\
\hline
\end{tabular}

\begin{tabular}{l|c|c|c}
\multicolumn{4}{c|}{$X^{2}=5.985 / p=.0,425$} \\
\hline ESCOLARIDADE & & & \\
\hline Até ㅇ grau c. $^{\text {o }}$ & 33,3 & 37,2 & 29,5 \\
\hline Até 2o grau c. & 17,9 & 44,2 & 37,8 \\
\hline Superior (completo+incompleto) & 18,7 & 34,7 & 46,7
\end{tabular}

\begin{tabular}{l|c|c|c}
\hline \multicolumn{4}{c}{$X^{2}=24.438 / p=.000$} \\
\hline TEMPO DE OP & & & \\
\hline Nunca/Não resp. & 25,4 & 40,8 & 33,8 \\
\hline Até 2 anos & 20,3 & 28,1 & 51,6 \\
\hline Acima de 2 anos & 20,0 & 36,0 & 44,0 \\
\hline \multicolumn{4}{c}{$X^{2}=8.775 / p=.067$} \\
\hline
\end{tabular}

Fonte: NUPESAL (2000)

*SM = Salários Mínimos

Entretanto, como a significância estatística no teste de associação envolvendo o tempo de OP retornou valor muito próximo do nível mínimo exigido, consideramos pertinente continuar a análise dessa relação por meio de modelos mais sofisticados. Para tanto, primeiramente tratamos de recodificar a medida de confiança somando as opções "depende" e "não confia". Obtivemos uma variável binária que distingue apenas os que "confiam" e os que "não confiam". Confirmando inicialmente nossa intuição, ao rodarmos um modelo simples de regressão logística contendo apenas o tempo de OP como medida preditora (Modelo 1 da Tabela 2) 
encontramos resultado significativo. Mais especificamente, cada elevação na escala de tempo no OP aumenta em 17,5\% a chance de o entrevistado compor o grupo dos que confiam.

Tabela 2 - Preditores da confiança interpessoal

\begin{tabular}{|c|c|c|c|c|c|c|}
\hline & \multicolumn{2}{|c|}{ Modelo 1} & \multicolumn{2}{|c|}{ Modelo 2} & \multicolumn{2}{|c|}{ Modelo 3} \\
\hline & $\operatorname{Exp}(B)$ & Sig & $\operatorname{Exp}(B)$ & Sig. & $\operatorname{Exp}(B)$ & Sig. \\
\hline Tempo de OP & 1.175 & .047 & 1.128 & .190 & 1.120 & .225 \\
\hline Escolaridade & & & 1.119 & .060 & 1.131 & .041 \\
\hline Renda Familiar & & & 1.000 & .198 & 1.000 & .276 \\
\hline Sexo & & & & & .790 & .256 \\
\hline Idade & & & & & 1.006 & .353 \\
\hline Pseudo $\mathrm{R}^{2}$ & \multicolumn{2}{|c|}{.011} & \multicolumn{2}{|c|}{.065} & \multicolumn{2}{|c|}{.037} \\
\hline
\end{tabular}

Fonte: NUPESAL (2000)

Para identificar a consistência desse efeito, na sequência construímos um modelo logístico múltiplo com a introdução das variáveis escolaridade e renda (Modelo 2 da Tabela 2). Confirmando o resultado da análise de associação que apresentamos anteriormente, com a inclusão dessas variáveis de controle, o efeito deixa de ser significativo. $\mathrm{O}$ mesmo se dá quanto introduzimos o sexo e a idade dos entrevistados (Modelo 3 da Tabela 2). É interessante notar que nesse modelo mais completo apenas a escolaridade produz efeito significativo. Cada elevação de nível na escolarização dos entrevistados produz um efeito de $13,1 \%$ na chance de comporem o grupo dos que confiam ${ }^{13}$.

A partir desses resultados concluímos que o tempo de participação no OP não é um bom preditor dessa primeira variável e que a escolaridade permanece como única variável relevante.

13 O modelo de regressão logística tem como exigência a inexistência de colinearidade perfeita entre os preditores, ou seja, é menos rigoroso do que os modelos lineares. Ainda assim, buscamos identificar se tais variáveis se encontraram muito relacionadas e constatamos que o maior coeficiente de correlação foi -.32 entre escolaridade e renda. Como isso, consideramos afastado o maior problema em relação às nossas conclusões, ou seja, a existência de forte associação entre tempo de OP e escolaridade. 
Orçamento Participativo e Cultura Política: Explorando as relações entre inovação institucional, valores e atitudes políticas

Julian Borba • Ednaldo Aparecido Ribeiro

A Tabela 3 analisa as variáveis relativas à confiança nas instituições a partir de dois indicadores. O primeiro é a confiança nos partidos políticos, instituição política que geralmente possui as piores avaliações nas pesquisas de cultura política. O cruzamento dessa variável com renda, escolaridade e tempo de OP revelou associação significativa apenas em relação a essa última. Como a codificação da confiança inicia-se com o "muito", o coeficiente Gamma negativo (-.288) indica que elevações na escala que mede o tempo de envolvimento no OP produz elevação no nível de confiança nos partidos.

Tabela 3 - Associações entre renda/escolaridade/tempo de OP e confiança nos partidos políticos/instituições municipais (\%)

\begin{tabular}{|c|c|c|c|c|c|c|}
\hline \multirow[b]{3}{*}{ RENDA } & \multicolumn{6}{|c|}{ CONFIANÇA } \\
\hline & \multicolumn{3}{|c|}{ PARTIDOS POLÍTICOS } & \multicolumn{3}{|c|}{$\begin{array}{l}\text { GOVERNO MUNICIPAL + } \\
\text { CÂMARA DE VEREADORES }\end{array}$} \\
\hline & Muito & Médio & Pouco & Baixa & Média & Alta \\
\hline Menos de $1 \mathrm{SM}$ & 6,4 & 34,0 & 59,6 & 42,4 & 40,3 & 17,3 \\
\hline De 1 a 5 SM & 11,8 & 36,6 & 51,6 & 40,9 & 38,7 & 20,4 \\
\hline De 5 a 10 SM & 6,4 & 46,8 & 46,8 & 34,0 & 34,9 & 31,1 \\
\hline \multirow[t]{2}{*}{ Mais de $10 \mathrm{SM}$} & 6,1 & 41,5 & 52,4 & 35,4 & 37,2 & 27,4 \\
\hline & \multicolumn{3}{|c|}{$X^{2}=8.07 / p=0.232$} & \multicolumn{3}{|c|}{$X^{2}=8.319 / p=0.216$} \\
\hline ESCOLARIDADE & Muito & Médio & Pouco & Baixa & Média & Alta \\
\hline Até 1o grau completo & 7,5 & 34.0 & 58.5 & 48.2 & 35.4 & 16.4 \\
\hline Até $2^{o}$ grau completo & 7.1 & 43.9 & 49.0 & 36.8 & 38.7 & 24.5 \\
\hline \multirow[t]{2}{*}{ Superior } & 7.2 & 42.8 & 50.0 & 26.3 & 40.1 & 33.6 \\
\hline & \multicolumn{3}{|c|}{$X^{2}=4.557 / p=0.336$} & \multicolumn{3}{|c|}{$\begin{array}{c}X^{2}=21.835 / p=0.00 \\
\text { Gamma }=0,279 / p=0.000\end{array}$} \\
\hline TEMPO DE OP & Muito & Médio & Pouco & Baixa & Média & Alta \\
\hline Nunca/Não respondeu & 6.1 & 37.9 & 56.0 & 39.8 & 39.1 & 21.1 \\
\hline Até 2 anos & 6.2 & 40.0 & 53.8 & 32.8 & 36.2 & 21.0 \\
\hline \multirow[t]{2}{*}{ Acima de 2 anos } & 20.4 & 53.1 & 26.5 & 24.5 & 36.7 & 38.8 \\
\hline & \multicolumn{3}{|c|}{$X^{2}=21.543 / p=.0,000$} & $\begin{array}{c}X^{2}= \\
\text { Gamma }\end{array}$ & $X^{2}=10.217 / p=0.037$ & $\begin{array}{l}0.037 \\
=0.004\end{array}$ \\
\hline
\end{tabular}

Fonte: NUPESAL (2000) 
O segundo indicador utilizado foi um índice de confiança nas instituições municipais, elaborado a partir da resposta à questão relativa à confiança na Câmara de Vereadores e à confiança no Governo Municipal. A expectativa, nesse sentido, era que os efeitos da participação do OP fossem maiores, pois, uma de suas características é promover a aproximação dos cidadãos para com o poder público, de modo que os primeiros teriam possibilidades de conhecer e, consequentemente, mais chances de confiar nas instituições.

Os dados da análise bivariada apontam (Tabela 3) mais uma vez para o efeito nulo da renda. Os cruzamentos com escolaridade e tempo de OP, todavia, revelam relacionamento positivo, indicando que os mais escolarizados e envolvidos há mais tempo nessa inovação institucional confiam mais.

Para aprofundar nossa compreensão sobre essas associações, passamos a construção de modelos de regressão que possam indicar com maior precisão o efeito de cada uma dessas variáveis independentes sobre a confiança nessas instituições. No caso dos partidos políticos inicialmente recodificamos a variável agrupando as opções "médio" e "pouco". Construímos uma variável binária que foi incluída em um modelo logístico que indicará os efeitos de medidas preditoras sobre a probabilidade de os entrevistados estarem entre os que confiam nos partidos.

O Modelo 1 (Tabela 4) toma como único preditor o tempo de $\mathrm{OP}$ e, confirmando o resultado do teste de associação anterior, mostra que cada elevação na escala dessa variável aumenta em 30,4\% a probabilidade do entrevistado compor o grupo dos que confiam nos partidos. O Modelo 2, construído pela inclusão da escolaridade e da renda, confirma a consistência desse efeito, apesar de uma redução de 10 pontos percentuais no efeito. Apenas no Modelo 3, com a inclusão de sexo e idade, o efeito deixa de ser estatisticamente significativo. Nessa equação mais completa, entretanto, nenhuma das variáveis alcançou o nível desejado de significância. 


\section{Orçamento Participativo e Cultura Política: Explorando as relações entre inovação institucional, valores e atitudes políticas \\ Julian Borba • Ednaldo Aparecido Ribeiro}

Tabela 4 - Preditores da confiança nos partidos

\begin{tabular}{|c|c|c|c|c|c|c|}
\hline & \multicolumn{2}{|c|}{ Modelo 1} & \multicolumn{2}{|c|}{ Modelo 2} & \multicolumn{2}{|c|}{ Modelo 3} \\
\hline & $\operatorname{Exp}(B)$ & Sig & $\operatorname{Exp}(B)$ & Sig. & $\operatorname{Exp}(B)$ & Sig. \\
\hline Tempo de OP & 1.304 & .002 & 1.201 & .049 & 1.180 & .078 \\
\hline Escolaridade & & & 1.040 & .493 & 1.034 & .567 \\
\hline Renda Familiar & & & 1.000 & .106 & 1.000 & .100 \\
\hline Sexo & & & & & .964 & .854 \\
\hline Idade & & & & & .998 & .777 \\
\hline Pseudo $\mathrm{R}^{2}$ & \multicolumn{2}{|c|}{.028} & \multicolumn{2}{|c|}{.028} & \multicolumn{2}{|c|}{.031} \\
\hline
\end{tabular}

Fonte: NUPESAL (2000)

Quanto à confiança nas instituições municipais primeiramente recodificamos as variáveis para que a ordem das opções se invertesse. Assim, o "muito" passa a ser igual 2, o "mais ou menos" passa a representar 1 e o "não confia" equivale a 0 . A partir dessa nova codificação construímos um índice somatório que vai de 0 a 4, indicando níveis crescentes de confiança. Tal redução foi considerada pertinente a partir dos resultados obtidos com o teste alpha Crombach (.699).

O Modelo 1 (Tabela 5), contendo apenas o tempo de OP, mostra que o efeito é significativo em um nível bastante exigente (.001) e que cada ponto na escala produz elevação de (.167) desvio-padrão na índice de confiança. Com a inclusão de escolaridade e renda (Modelo 2), a variável do OP continua importante, mas perde para a escolaridade na comparação da intensidade dos efeitos. Resultados semelhantes são encontrados no Modelo 3, ao qual adicionamos sexo e idade. Apenas tempo de OP e escolaridade continuam apresentando efeitos significativos, sendo o impacto dessa última de maior magnitude ${ }^{14}$.

14 Preocupados com o possível problema de multicolinearidade envolvendo principalmente os preditores tempo de OP e escolaridade realizamos o teste condition index que retornou como maior valor 9,39, muito inferior ao 30,0, descrito pela literatura como patamar preocupante. 
Tabela 5 - Preditores da confiança nas instituições municipais

\begin{tabular}{|c|c|c|c|c|c|c|}
\hline & \multicolumn{2}{|c|}{ Modelo 1} & \multicolumn{2}{|c|}{ Modelo 2} & \multicolumn{2}{|c|}{ Modelo 3} \\
\hline & Beta & Sig & Beta & Sig. & Beta & Sig. \\
\hline Tempo de OP & .154 & .001 & .115 & .018 & .115 & .019 \\
\hline Escolaridade & & & .148 & .004 & .157 & .002 \\
\hline Renda Familiar & & & .079 & .121 & .070 & .173 \\
\hline Sexo & & & & & -.011 & .819 \\
\hline Idade & & & & & .059 & .234 \\
\hline $\mathrm{R}^{2}$ & \multicolumn{2}{|c|}{.024} & \multicolumn{2}{|c|}{.050} & \multicolumn{2}{|c|}{.054} \\
\hline
\end{tabular}

Fonte: NUPESAL (2000)

\subsection{Sociedade Politizada}

O primeiro teste foi relativo ao índice de participação política eleitoral. Nesse sentido, buscava-se identificar qual o melhor preditor para o envolvimento político eleitoral do cidadão. Como se sabe, a literatura sobre participação política tendeu historicamente a identificar fortes associações entre variáveis socioeconômicas e envolvimento político, sendo que tal relação foi teorizada através do que ficou conhecido como modelo da centralidade (MILBRATH, 1965). No caso em questão, os resultados da análise bivariada (Tabela 6) não corroboram com a teoria da centralidade, pois renda mais uma vez não se associa à participação eleitoral. Já escolaridade apresenta uma associação não desprezível, mas fraca entre as variáveis (gama 0,242 ). Por fim, a medida tempo de participação no OP apresenta uma forte associação com participação eleitoral (gama 0,672 ). Considerando esses dados, acreditamos ter importantes indicadores no sentido de validar as teorias da participação política que apelam para o papel desempenhado pelas identidades políticas construídas ao longo do processo de socialização dos indivíduos ${ }^{15}$.

15 Por questões de espaço não temos condições de desenvolver com mais calma o argumento. Para maiores detalhes sobre o papel da identidade na explicação da participação política, vide Pizzorno (1985). 
Orçamento Participativo e Cultura Política: Explorando as relações entre inovação institucional, valores e atitudes políticas

Julian Borba • Ednaldo Aparecido Ribeiro

Tabela 6 - Associações entre renda/escolaridade/tempo de OP e o índice de participação eleitoral

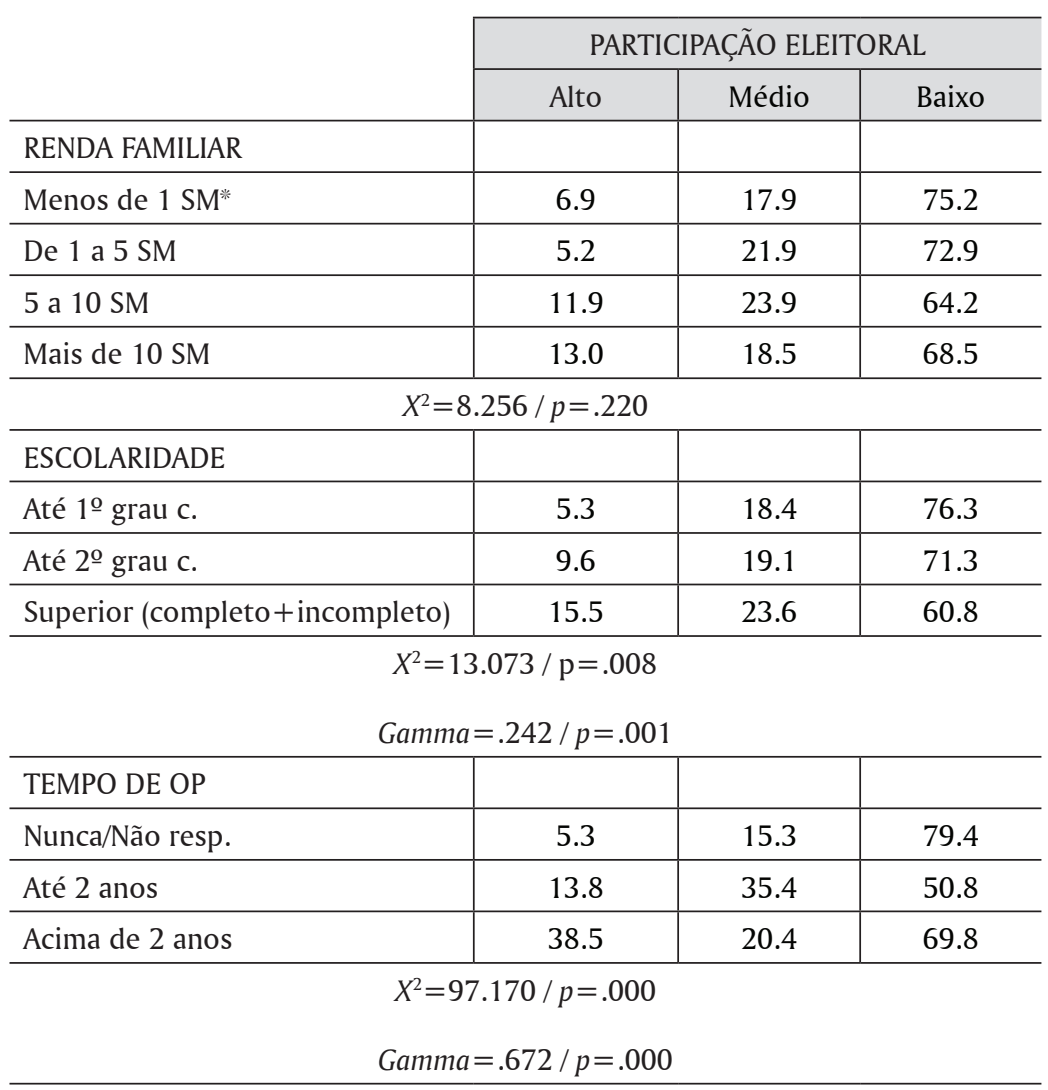

Fonte: NUPESAL (2000)

Esses resultados foram amplamente confirmados pela análise de regressão (Tabela 7). O Modelo 1, contendo apenas o tempo de OP, mostra que o seu impacto sobre a participação eleitoral é significativo e que cada elevação produz efeito positivo de (.424) desvios-padrão. Ao incluirmos escolaridade e renda, compondo um modelo multivariado (Modelo 2) esse resultado é confirmado. É relevante mencionar que nem mesmo a escolaridade conseguiu atingir o nível mínimo de significância estatística nessa análise (.053). O Modelo 3, construído 
com a adição de sexo e idade, apresenta resultados semelhantes, apesar de uma redução no efeito do tempo de OP. Mas essa variável continua sendo o levante da participação eleitoral.

Tabela 7 - Preditores da participação política eleitoral

\begin{tabular}{l|c|c|c|c|c|c}
\cline { 2 - 7 } & \multicolumn{2}{|c|}{ Modelo 1 } & \multicolumn{2}{c|}{ Modelo 2 } & \multicolumn{2}{c}{ Modelo 3 } \\
\hline & Beta & Sig. & B & Sig. & B & Sig. \\
\hline Tempo de OP & .424 & .000 & .373 & .000 & .369 & .000 \\
\hline Escolaridade & & & .092 & .053 & .091 & .060 \\
\hline Renda Familiar & & & .043 & .366 & .042 & .386 \\
\hline Sexo & & & & & .050 & 271 \\
\hline Idade & \multicolumn{2}{|c|}{} & & & -.021 & .648 \\
\hline $\mathrm{R}^{2}$ & \multicolumn{2}{|c|}{} & \multicolumn{3}{c}{.155} & \multicolumn{3}{c}{.153} \\
\hline
\end{tabular}

Fonte: NUPESAL (2000)

Testamos também o efeito das variáveis independentes sobre o interesse por política e sobre o modelo de decisão do voto (Tabela 8). No que diz respeito à primeira, os testes bivariados revelaram associações entre todas as variáveis, ou seja, quanto maior a escolaridade (Gamma .587) e maior o tempo de OP (Gamma .376), e renda (Gamma .257) maior também é o interesse por política dos entrevistados. 
Orçamento Participativo e Cultura Política: Explorando as relações entre inovação institucional, valores e atitudes políticas

Julian Borba • Ednaldo Aparecido Ribeiro

Tabela 8 - Associações entre renda/escolaridade/tempo de OP e interesse por política/decisão do voto.

\begin{tabular}{|c|c|c|c|c|c|}
\hline & \multicolumn{3}{|c|}{ INTERESSE POR POLÍTICA } & \multicolumn{2}{|c|}{ DECISÃO DO VOTO } \\
\hline RENDA & Nenhum & Médio & Alto & Pessoa & Partido \\
\hline Menos de $1 \mathrm{SM}$ & 22.8 & 59.1 & 18.1 & 42.7 & 30.0 \\
\hline De 1 a 5 SM & 26.8 & 64.9 & 8.2 & 70.1 & 24.7 \\
\hline De 5 a 10 SM & 16.2 & 61.3 & 22.5 & 37.8 & 37.8 \\
\hline \multirow[t]{2}{*}{ Mais de $10 \mathrm{SM}$} & 10.3 & 58.3 & 31.0 & 23.0 & 29.3 \\
\hline & \multicolumn{3}{|c|}{$X^{2}=28536 / p=.000$} & $\begin{array}{l}X^{2}=78 \\
\text { Gamma }\end{array}$ & $\begin{array}{l}/ p=.216 \\
8 / p=.000\end{array}$ \\
\hline ESCOLARIDADE & Nenhum & Médio & Alto & Pessoa & Partido \\
\hline Até $1^{\circ}$ grau completo & 29.9 & 59.1 & 18.1 & 76.1 & 23.9 \\
\hline Até $2^{\circ}$ grau completo & 15.5 & 66.5 & 18.0 & 66.9 & 33.1 \\
\hline \multirow[t]{2}{*}{ Superior } & 4.5 & 51.3 & 44.2 & 54.7 & 45.3 \\
\hline & \multicolumn{3}{|c|}{$X^{2}=94.434 / \mathrm{p}=.000$} & \multicolumn{2}{|c|}{$X^{2}=78.381 / p=.000$} \\
\hline TEMPO DE OP & Nenhum & Médio & Alto & Pessoa & Partido \\
\hline Nunca/Não respondeu & 20.1 & 62.4 & 17.5 & 71.9 & 28.1 \\
\hline Até 2 anos & 17.9 & 59.7 & 22.4 & 54.0 & 46.0 \\
\hline \multirow[t]{2}{*}{ Acima de 2 anos } & 3.8 & 44.2 & 51.9 & 48.9 & 51.1 \\
\hline & \multicolumn{2}{|c|}{$X^{2}=21.543 / p=.0,000$} & $\begin{array}{l}, 000 \\
0.002\end{array}$ & $X^{2}=15.070 / p=.001$ & $\begin{array}{l}/ p=.001 \\
4 / p=.000\end{array}$ \\
\hline
\end{tabular}

Fonte: NUPESAL (2000)

As análises multivariadas confirmam quase que totalmente os resultados dos testes de associação. O Modelo 1 (Tabela 9), contendo apenas o tempo de OP, apontou resultados bastante satisfatórios, pois cada avanço na escala eleva em $25 \%$ a chance de o entrevistado estar entre os interessados em política. Incluindo renda e escolaridade, o efeito continua significativo (Modelo 2). O impacto continua sendo de mais de $20 \%$, porém é bem menor do que o provocado pela escolaridade. Cada elevação na escala 
de escolarização eleva em $70 \%$ a chance de compor o grupo dos interessados. A inclusão de sexo e idade (Modelo 3) não altera esse quadro, porém, vale apontar o efeito significativo de ser homem sobre o interesse $(60,1 \%)$.

Tabela 9 - Preditores do interesse por política

\begin{tabular}{l|c|c|c|c|c|c}
\cline { 2 - 7 } & \multicolumn{2}{|c|}{ Modelo 1 } & \multicolumn{2}{c|}{ Modelo 2 } & \multicolumn{2}{c}{ Modelo 3 } \\
\hline & $\operatorname{Exp}(\mathrm{B})$ & Sig. & $\operatorname{Exp}(\mathrm{B})$ & Sig. & $\operatorname{Exp}(\mathrm{B})$ & Sig. \\
\hline Tempo de OP & 1.250 & .010 & 1.236 & .044 & 1.233 & .049 \\
\hline Escolaridade & & & 1.703 & .000 & 1.690 & .000 \\
\hline Renda Familiar & & & 1.000 & .216 & 1.000 & .171 \\
\hline Sexo & & & & & 1.601 & .033 \\
\hline Idade & & & & & .989 & .108 \\
\hline Pseudo R & \multicolumn{2}{|c|}{.018} & \multicolumn{3}{c|}{.260} & \multicolumn{3}{c}{.280} \\
\hline
\end{tabular}

Fonte: NUPESAL (2000)

Com relação ao voto partidário, a análise bivariada indica associações positivas com a participação no OP (Gamma 0,384$)$ e, em menor grau, com a escolaridade (Gamma 0,318) e renda (Gamma 0,298). Os resultados das análises de regressão corroboram tais achados (Tabela 10), pois no Modelo 1 verificamos que cada elevação no tempo de participação no OP eleva as chances de voto no partido em $34,9 \%$. Com a inclusão de renda e escolaridade, compondo o Modelo 2, o efeito do OP continua significativo, provocando aumento de $22,6 \%$ na probabilidade. $O$ interessante é que a escolaridade não afeta o voto no partido, sendo substituída por renda familiar. Mesmo no Modelo 3, com sexo e idade adicionados, o efeito da variável relativa ao OP continua sendo o preditor mais relevante. 
Orçamento Participativo e Cultura Política: Explorando as relações entre inovação institucional, valores e atitudes políticas

Julian Borba • Ednaldo Aparecido Ribeiro

Tabela 10 - Preditores do voto partidário

\begin{tabular}{l|c|c|c|c|c|c}
\cline { 2 - 7 } & \multicolumn{2}{c|}{ Modelo 1 } & \multicolumn{2}{c|}{ Modelo 2 } & \multicolumn{2}{c}{ Modelo 3 } \\
\hline & $\operatorname{Exp}(\mathrm{B})$ & Sig. & $\operatorname{Exp}(\mathrm{B})$ & Sig. & $\operatorname{Exp}(\mathrm{B})$ & Sig. \\
\hline Tempo de OP & 1.349 & .000 & 1.226 & .031 & 1.239 & .026 \\
\hline Escolaridade & & & 1.083 & .216 & 1.073 & .284 \\
\hline Renda Familiar & & & 1.000 & .028 & 1.000 & .023 \\
\hline Sexo & & & & & 1.211 & .390 \\
\hline Idade & & & & & .988 & .093 \\
\hline Pseudo R ${ }^{2}$ & \multicolumn{2}{|c|}{.037} & \multicolumn{3}{c}{.048} & \multicolumn{3}{c}{.058} \\
\hline
\end{tabular}

Fonte: NUPESAL (2000)

\subsection{Associações}

O último indicador foi o de participação em associações. Nesse caso, também era de se esperar um efeito positivo do tempo de OP sobre o associativismo. Os dados da análise bivariada (Tabela 11) confirmaram a expectativa, apontando para uma associação de intensidade moderada à forte entre o tempo de participação no OP e a participação em associações. As variáveis renda e escolaridade não apresentaram qualquer associação com a variável em questão. Nesse sentido, considerando que a participação em associações é fundamental para a existência de uma comunidade cívica, o fato de o indivíduo participar do OP parece isolar os efeitos desagregadores da baixa renda e escolaridade. 
Tabela 11 - Associações entre renda, escolaridade e tempo de OP e participação em associações

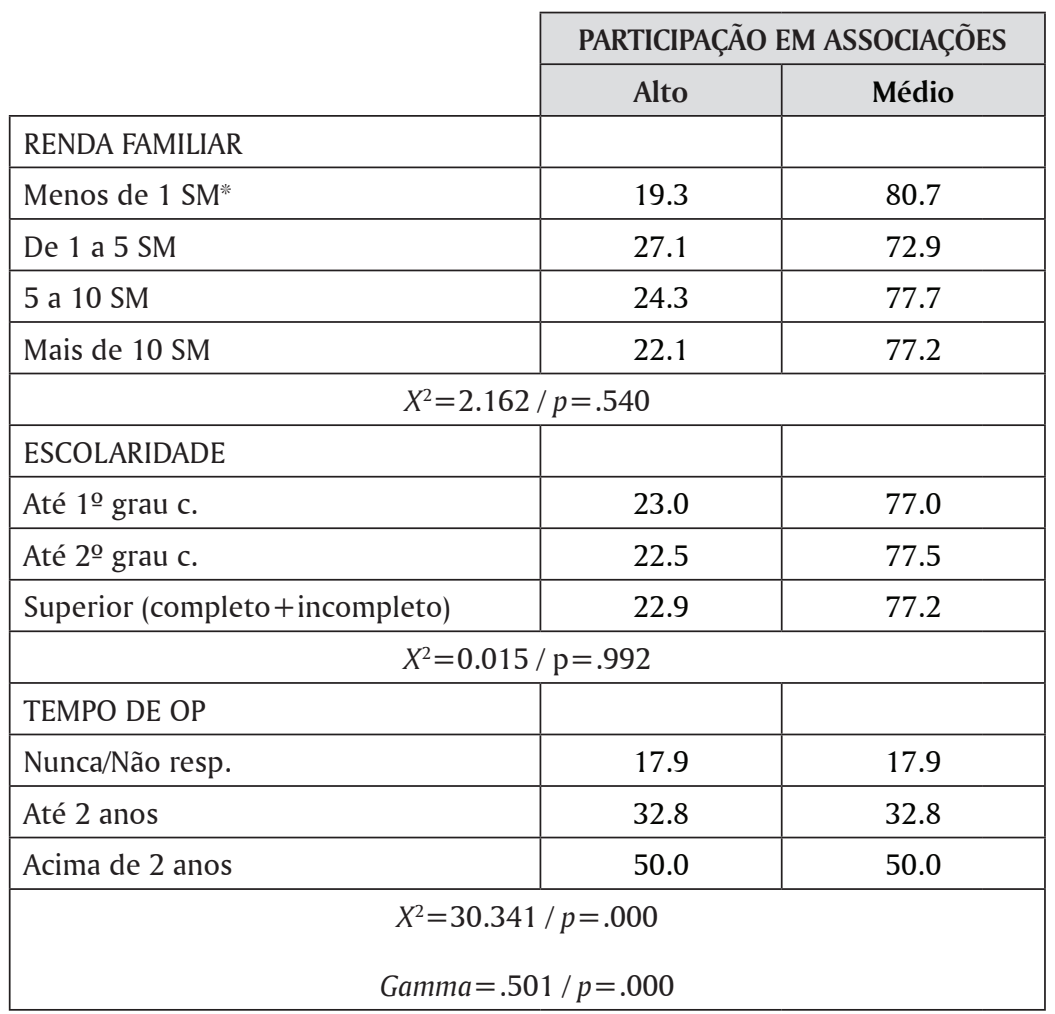

Fonte: NUPESAL (2000)

Os dados do modelo de regressão reafirmam tais resultados (Tabela 12). No Modelo 1, contendo o tempo de OP como variável dependente, cada elevação na escala do preditor eleva em 54,5\% a chance de participar de associações. Com a inclusão de renda e escolaridade (Modelo 2) os resultados indicam que apenas o OP continua como relevante, ainda que o seu efeito seja reduzido para $42,8 \%$. O quadro continua o mesmo com a inclusão de sexo e idade (Modelo 3). 
Orçamento Participativo e Cultura Política: Explorando as relações entre inovação institucional, valores e atitudes políticas

Julian Borba • Ednaldo Aparecido Ribeiro

Tabela 12 - Preditores da associação

\begin{tabular}{l|c|c|c|c|c|c}
\cline { 2 - 7 } & \multicolumn{2}{c|}{ Modelo 1 } & \multicolumn{2}{c|}{ Modelo 2 } & \multicolumn{2}{c}{ Modelo 3 } \\
\hline & $\operatorname{Exp}(\mathrm{B})$ & Sig. & $\operatorname{Exp}(\mathrm{B})$ & Sig. & $\operatorname{Exp}(\mathrm{B})$ & Sig. \\
\hline Tempo de OP & 1.545 & .000 & 1.428 & .000 & 1.414 & .000 \\
\hline Escolaridade & & & .958 & .532 & .973 & .685 \\
\hline Renda Familiar & & & 1.000 & .107 & 1.000 & .165 \\
\hline Sexo & & & & & 1.081 & .738 \\
\hline Idade & & & & & 1.009 & .228 \\
\hline Pseudo R ${ }^{2}$ & \multicolumn{2}{|c}{.077} & \multicolumn{3}{c}{.059} & \multicolumn{3}{c}{.062} \\
\hline
\end{tabular}

Fonte: NUPESAL (2000)

\section{Considerações finais}

Como já destacado, o OP vem se constituindo em uma importante inovação institucional da democracia brasileira. Mais de uma centena de municípios já implantaram esse modelo de definição do orçamento público no Brasil (RIBEIRO; GRAZIA, 2003). Os defensores de tal modelo justificam sua adoção por diferentes motivos: racionalizar o gasto público, universalizar procedimentos, produzir accountability, "produzir" cidadania, promover educação política democrática, desenvolver o espírito e engajamento cívico etc.

Veja-se que entre esses motivos, os relacionados à dimensão política, do "civismo", são os que mais se destacam. Apesar disso, foram poucos os autores que trataram do assunto através de pesquisa empírica com amostras representativas da população local, onde participantes e não participantes do OP são comparados e os últimos utilizados como variável de controle.

Partindo desse diagnóstico, buscamos analisar empiricamente a relação entre OP, comunidade cívica e capital social. Para isso, buscamos operacionalizar o estudo através de uma série de testes, que permitiram chegar às seguintes constatações:

a) A variável renda mostrou a maior capacidade preditiva para o voto partidário e se mostrou significante para explicar informação; 
b) Sexo somente se mostrou significante para explicar interesse por política;

c) A variável escolaridade se mostrou como a melhor preditora para confiança interpessoal, confiança nos partidos, confiança nas instituições municipais e interesse por política;

d) O tempo de OP se mostrou com maior capacidade preditiva para participação política eleitoral e participação em associações, mas também se mostrou relevante para as dimensões da confiança nas instituições municipais e interesse por política.

Que tipo de conclusão podemos extrair de tais dados?

a) Em primeiro lugar, eles confirmam um conjunto de teorizações já consagradas na moderna ciência política que identificam na centralidade social do indivíduo, o principal determinante de suas atitudes, valores e comportamento. Em nosso estudo, a tese da centralidade ficou evidenciada pela dimensão da escolaridade que se mostrou a de maior capacidade preditiva para a maioria das variáveis;

b) A novidade do estudo foi apontar que o tempo de participação no Orçamento Participativo pode exercer semelhante influência à escolaridade na produção de atitudes e valores cívicos. Em algumas variáveis, mostrou-se superior a ela, como no caso do associativismo (onde escolaridade nem apresentou significância) e voto partidário. Acreditamos que esses resultados complementam as conclusões a que os estudos sobre o OP já haviam chegado, utilizando-se apenas de amostragens com ativistas. $O$ ganho analítico, em nosso caso, está relacionado à capacidade de generalização dos resultados ao utilizar uma amostragem representativa da população local, incluindo os não ativistas.

c) Em termos da discussão teórica sobre o capital social, o que nossos resultados apontaram é que, de forma contrária ao 


\section{Orçamento Participativo e Cultura Política: Explorando as relações entre inovação institucional, valores e atitudes políticas \\ Julian Borba • Ednaldo Aparecido Ribeiro}

previsto por Putnam e colaboradores, inovações institucionais podem sim promover alterações em padrões atitudinais e comportamentais, mesmo em curto espaço de tempo. As constatações acima permitem corroborar interpretações como as de Fedozzi (2002) e Luchmann (2008) que indicam que o tempo de participação no OP produz aprendizado político, constituindo-se num espaço de socialização política alternativa capaz de minorar os efeitos negativos da baixa escolaridade sobre as atitudes e comportamentos políticos da cidadania.

É claro que tal interpretação tem que ser relativizada, tendo em vista que uma série de limites pode ser identificada nos dados. O principal deles refere-se à direção da relação causal. Com os testes realizados, não temos condições de afirmar que os padrões observados devem-se, no caso específico, à participação no OP. A relação pode se dar no sentido inverso, ou seja, é possível que os indivíduos que participam do OP sejam aqueles que já possuam maior confiança nas instituições, informação política, associados etc. Uma das maneiras de resolver esse problema seria através da realização de pesquisas do tipo painel, onde se pode observar o comportamento dos atores em diferentes períodos. Como não dispúnhamos desse tipo de dado, salientamos para os limites de nossa análise.

\section{Referências}

ABERS, R. Do clientelismo à cooperação: governos locais, políticas participativas e organização da sociedade civil em Porto Alegre. Cadernos do IPPUR, Rio de Janeiro, v. 7, n. 1, p. 37-42, jan./jul. 1998.

AVRITZER, L; NAVARRO, Z. (Orgs.). A inovação democrática no Brasil. São Paulo: Cortez, 2003. 
AVRITZER, L. Democracy and the public space in Latin America. Princeton: Princeton University Press, 2002.

AVRITZER, L. Participatory Institutions in Democratic Brazil. Baltimore: John Hopkins University Press, 2009.

BAIOCCHI, G. Emergent public spheres: talking politics in participatory governance. American Sociological Review, v. 68, n. 1, p. 52-74, 2003.

. Militants and citizens: the politics of participation in Porto Alegre. Stanford: University Press, 2005.

BANCO MUNDIAL. Rumo a um orçamento participativo mais inclusivo e efetivo em Porto Alegre. Washington DC, 2008. Disponível em: <http://www-wds.worldbank.org > Acesso em: jul. 2011.

BAQUERO, M. et al. Bases de um novo contrato social? Impostos e Orçamento Participativo em Porto Alegre. Opinião Publica, Campinas, v. 11, n. 1, p. 94-127, mar. 2005.

BAQUERO, M. Capital social y cultura política en Brasil: posibilidades y limites. In: América Latina Hoy, v. 33, abr. 2003.

BORBA, J.; LUCHMANN, L. H. H. (Org.). Orçamento Participativo: análise das experiências desenvolvidas em Santa Catarina. Florianópolis: Insular, 2007.

EVANS, P. Government action, social capital and development: reviewing the evidence on sinergy. In: World Development, v. 24, n. 6, 1996.

FEDOZZI, L. Orçamento participativo: reflexões sobre a experiência de Porto Alegre. Porto Alegre: Tomo editorial, Rio de Janeiro: Observatório de políticas urbanas e gestão municipal (FASE/IPPUR), 1997.

FEDOZZI, L. O “eu e os outros": a construção da consciência social dos participantes do Orçamento Participativo de Porto Alegre. 
Orçamento Participativo e Cultura Política: Explorando as relações entre inovação institucional, valores e atitudes políticas

Julian Borba • Ednaldo Aparecido Ribeiro

Tese (Doutorado em Sociologia) - Programa de Pós-Graduação em Sociologia, Universidade Federal do Rio Grande do Sul, Porto Alegre, 2002.

FEDOZZI, L. J. Observando o Orçamento Participativo de Porto Alegre. Análise histórica de dados: perfil social e associativo, avaliação e expectativas. Porto Alegre: Tomo Editorial, 2007.

GUGLIANO, A.; MAURICH, M. R.; VENEZIANO, A. E. LOECK, R. Trajetórias dos orçamentos participativos: notas sobre os processos de Porto Alegre, Montevidéu e Buenos Aires. Ensaios FEE (Impresso), v. 31, 2010.

HARTMANN, F. C. Aprendizado político e democrático no Orçamento Participativo de Concórdia/SC. Dissertação (Mestrado em Sociologia Política) - Programa de Pós-Graduação em Sociologia Política, Universidade Federal de Santa Catarina, Florianópolis, 2011.

HOOG, M.; STOLLE, D. Introduction. In: HOOG, M.; STOLLE, D. Generating social capital. New York: Palgrave, Macmillan, 2003.

KRISCHKE, P. J. A cultura política em Porto Alegre e Curitiba: democracia, modernização e o conteúdo da razão pública. Sociedade \& Estado, Brasília, v. 20, n. 1. p. 39-71, abr. 2005.

KRISCHKE, P.J. Cultura política: convergências e diferenças em Porto Alegre e Curitiba. Revista de Ciências Humanas, Florianópolis, n. 35, jul./dez., p. 141-176, 2004.

LÜCHMANN, L. H. Possibilidades e limites da democracia deliberativa: a experiência do Orçamento Participativo de Porto Alegre. Tese (Doutorado em Ciências Sociais) - Universidade de Campinas, 2002.

LÜCHMANN, L; H. Democracia participativa e aprendizado político: lições da experiência brasileira. Florianópolis, 2008 (mimeo). Disponível em: <www.npms.ufsc.br>. Acesso em: 18 jun. 2012. 
MILBRATH, L. Political Participation: How and why do people get involved in politics? Chicago: Rand McNally, 1965.

NUCLEO DE PESQUISAS SOBRE A AMÉRICA LATINA (NUPESAL). Comportamento político e eleições. Porto Alegre, UFRGS, 2000. [Base de Dados]

PIZZORNO, A. Algum tipo diferente de diferença: uma crítica das teorias da escolha racional. In: FOXLEY, A; McPHERSON, M; O'DONNELL, G. Desenvolvimento, política e aspirações sociais. O pensamento de Albert Hirschman. São Paulo: Vértice, 1985.

PONTUAL, P. C. O processo educativo no Orçamento Participativo: aprendizados dos atores da sociedade civil e do estado. Tese (Doutorado em Educação) - Pontifícia Universidade Católica de São Paulo, 2000.

POWERS, D. A.; XIE, Y. Statistical methods for categorical data analysis. London: Emeral, 2008.

PUTNAM, R. et al. Comunidade e democracia: a experiência da Itália moderna. Rio de Janeiro: FGV, 2002.

REIS, B.W. Capital social e confiança: questões de teoria e método. Revista de Sociologia \& Política, Curitiba, n. 21, p. 35-49, nov. 2003.

RENNO, L. Os militantes são mais informados? Desigualdade e informação política nas eleições de 2002. Opin. Publica, Campinas, v. 12, n. 2, nov. 2006. Disponível em: <http:// homolog.scielo.br/scielo.php?script $=$ sci_arttext $\&$ pid $=$ S0104$62762006000200005 \& \operatorname{lng}=p t \& n r m=$ iso $>$. Acesso em: 5 jul. 2011. doi: 10.1590/S0104-62762006000200005.

RIBEIRO, A. C. \& GRAZIA, G. Experiências de Orçamento Participativo no Brasil. Período: 1997-2000. Petrópolis: Vozes, 2003.

ROHESTEIN, B. \& STOLLE, D. Social capital, impartiality and welfare state: an institutional approach. In: HOOG, M. \& STOLLE, D. Generating social capital. New York: Palgrave, Macmillan, 2003. 
Orçamento Participativo e Cultura Política: Explorando as relações entre inovação institucional, valores e atitudes políticas

Julian Borba • Ednaldo Aparecido Ribeiro

ROHESTEIN, B. Social capital in the social democratic welfare. In: Politics \& Society, v. 29, n. 2, 2001.

SANTOS, A. M. Democracia e valores cívicos: uma relação necessária? In: Novos Estudos CEBRAP, n. 69, jul. 2004.

SANTOS, B. S. Participatory budgeting in Porto Alegre: toward a redistributive democracy. Politics \& Society, v. 26, n. 4, p. 461-510, 1998.

SALEJ, S. Fundamentos teóricos do capital social. 2005.

USLANER, E. M. Trust, democracy and governance: can government policies influence geneneralized trust? In: HOOG, M. \& STOLLE, D. Generating social capital. New York: Palgrave, Macmillan, 2003.

WAMPLER, B. e AVRITZER, L. Participatory publics: civil society and new institutions in democratic Brazil. Comparative Politics, v. 36, n. 3, 2004.

\section{Abstract \\ Participatory Budgeting and Political Culture: exploring the relation between institutional innovation and political values and attitudes}

Participatory Budgeting has been portrayed in the literature as an institutional innovation capable of producing institutional and cultural political impacts. Among the latter, we may point to its ability to changewellestablished patterns of political culture such as clientelism. The existing empirical data sustaining these affirmations are, in general, precarious. The present work aims to analyse the relationship between the PB and political culture, using as empirical base a survey conducted in the city of Porto Alegre in 2000. Multivariate data analysis techniques (regression model) were used, which allowed us to introduce proper explanatory elements into the analysis and to verify whether participation in the $\mathrm{PB}$, or the length of time of this participation, are good parameters for measuring civic culture and social capital.

Keywords: Democracy. Political culture. Participatory budgeting. Social capital. Public policy. 